\title{
Transabdominal Pre-peritoneal Mesh Repair versus Lichtenstein's Hernioplasty
}

\author{
Rajan Koju, ${ }^{1}$ Ram Bhakta Koju, ${ }^{2}$ Balaram Malla, ${ }^{1}$ Yashad Dongol, ${ }^{3}$ Lok Bikram Thapa ${ }^{1}$ \\ 1Department of General Surgery, Dhulikhel Hospital, Kathmandu University Hospital, Dhulikhel, Nepal, \\ ${ }^{2}$ Department of Anesthesia and Critical Care, KIST Medical College, Lalitpur, Nepal, ${ }^{3}$ Department of \\ Biochemistry, KIST Medical College, Lalitpur, Nepal
}

\begin{abstract}
Background: In the era of minimal invasive surgery, hernia repair has seen a paradigm shift from open to laparoscopic technique. However, superiority of laparoscopic repair over open repair is still controversial. Available literatures have shown laparoscopic technique to be better in term of post-operative pain and early return to work.

Methods: In this prospective study, a total of 102 patients aged 21-78 years with inguinal hernia were recruited and enrolled into two comparative groups, namely Lichtenstein's and Transabdominal pre-peritoneal, and each group containing 51 participants. Hospital ethical committee approval and written informed consent from patients was obtained. Primarily, the duration of operation, post-operative pain and complication, and quality of life after surgery was compared between the two different approaches of hernia repair.

Results: The study results demonstrated a statistically significant superiority of trans abdominal pre-peritoneal repair over Lichtenstein's hernioplasty in terms of post operative pain $(2.00 \pm 0.63$ vs $3.90 \pm 0.74 \mathrm{VAS}$ score, $\mathrm{P}$ value $<0.001)$, hospital stay $(2.33 \pm 0.62$ vs $2.96 \pm 0.20$ days, P value $<0.001)$ and quality of life with early return to normal work (13.39 \pm 0.60 vs $17.88 \pm 0.86$ days, $P$ value $<0.001)$; whereas a prolonged operative time was seen in transabdominal pre-peritoneal repair $(96.08 \pm 27.08$ vs $42.55 \pm 5.95$ mins, $\mathrm{P}$ value $<0.001)$.

Conclusions: This study has shown that transabdominal pre-peritoneal repair is better than Lichtenstein's in respect to post-operative pain, quality of life and post-operative complication. However, it has prolonged operative duration than conventional method.

Keywords: Hernioplasty, inguinal hernia, Lichtenstein's repair, TAPP: Transabdominal pre-peritoneal procedure.
\end{abstract}

\section{INTRODUCTION}

Hernia (Latin: rupture) is an abnormal protrusion of an organ or tissue through a defect in its surrounding walls. ${ }^{1}$ Inguinal hernia most probably has been a disease ever since mankind existed. ${ }^{2}$ Two thirds of inguinal hernia are indirect. An indirect inguinal hernia is the most common hernia regardless of gender. ${ }^{3}$ The surgical history of inguinal hernias dates back to ancient Egypt ${ }^{4}$ in 1883 to today's mesh based open and laparoscopic repairs, which parallels the evolution in anatomical understanding and development of techniques of general surgery. ${ }^{5,6}$ Laparoscopic repair was first reported by Ger in $1990 .^{7}$ There are three techniques of laparoscopic hernia repair, namely transabdominal pre-peritoneal repair (TAPP), totally extraperitoneal repair (TEP), and intraperitoneal onlay mesh repair (IPOM)Laparoscopic inguinal hernia repair has benefit of less postoperative pain, reduced recovery time, easier repair of a recurrent hernia, concurrent treatment of bilateral hernias, and improved cosmesis. ${ }^{8,9}$ Recurrence rate may be lower in TAPP as compared to open technique due to preperitoneal tension free mesh placement. ${ }^{10,11}$ This study was planned to reflect benefit of TAPP in our region.

\section{METHODS}

This was a prospective, quasi randomized hospital based study carried out from October 2012 to March 2014 at Dhulikhel Hospital. Written informed consent was taken from the patients willing to participate in the study. The enrolled patients were given numbers which was used to randomize the patients in two groups, namely 
Lichtenstein's and TAPP. Even number was assigned for Lichtenstein's hernioplasty and odd number for TAPP.

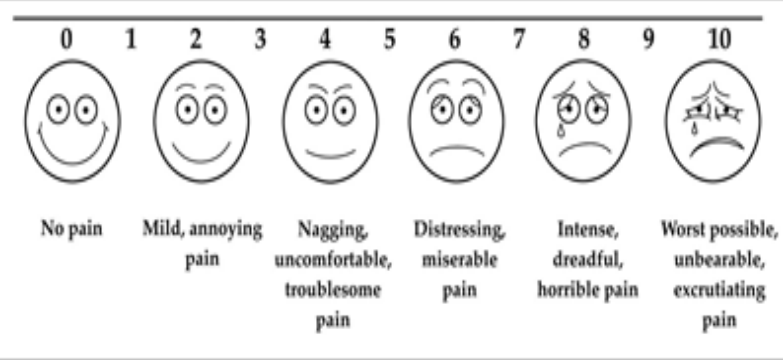

Figure 1. Visual analogue score (VAS).

All cases of inguinal hernia diagnosed by attending surgeon based on patient's history, clinical examination and relevant investigation were included whereas patients with congenital hernia, obstructed, incarcerated and strangulated inguinal hernia, contraindication to general anesthesia and those who did not give consent to participate in the study were excluded.

Lichtenstein's procedure was done under spinal anesthesia with transverse incision $1.25 \mathrm{~cm}$ above inguinal ligament from deep to superficial ring. Subarachnoid block was done with $3 \mathrm{ml}$ 0.5\% (15 mg) heavy bupivacaine after preloading with $1000 \mathrm{ml}$ crystalloid solution. Standard technique was followed for hernia repair and mesh was anchored with prolene 3-0 interrupted suture medially upto rectus sheath and first suture was taken at pubic tubercle.TAPP was done under GA (induced with fentanyl $2 \mathrm{mcg} / \mathrm{kg}$, propofol $2 \mathrm{mg} /$ $\mathrm{kg}$ and vecuronium $0.15 \mathrm{mg} / \mathrm{kg}$ then maintained with sevoflurane $1-1.5 \%$ and vecuronium).

Three ports were used (two $10 \mathrm{~mm}$ port, one in umbilical and other $10 \mathrm{~mm}$ port on the side of hernia at the midclavicular region at the level of umbilicus; one $5 \mathrm{~mm}$ port used in next side mid clavicular region at the level of umbilicus). Bilateral inguinal region visualized, then pre-peritoneal region was dissected on the hernia side. Sac was reduced then preformed mesh of variable size was used according to size of defect overlapping more than $2 \mathrm{~cm}$ on either side from the defect. ${ }^{12}$ Size of preformed mesh used were medium ( 3 by 5 inch), large ( 4 by 6 inch) and extra large ( 5 by 7 inch). Mesh was anchored with fructose tacker and peritoneal layer was closed with vilock suture.

After the surgery, patients in both groups were assessed for pain four-hourly using Visual Analogue Score (VAS); then cumulative score of 24 hours was calculated. Patients were followed up for 12 months, return to normal work were inquired with patient and noted.

Altogether there were 102 patients: 51 in Lichtenstein's group and 51 in TAPP group. The sample size of 51 in both groups was calculated using $G$ power $3.1^{*}$ to detect a medium effect size of 0.5 in pain scores for intervention and control with power of $80 \%$.

Data was collected on a structured performa covering the relevant subjects of the study. A detailed orientation of study and enrollment system was given to all doctors and ward in-charge for admitted patients by the principal investigator. After receiving a case fulfilling the inclusion criteria they were explained about the study in detail. Routine and specific laboratory tests were carried out using standard laboratory protocol.

Patients were admitted as per hospital protocol. The patients underwent hernia repair either Lichtenstein's or laparoscopically and operative findings were noted. The data was entered using SPSS 20 software. Statistical analysis was done using SPSS version 20 software. Results were presented in tables, graphs and diagrams. Chi square test was done. $P$ value less than 0.05 was termed as statistically significant.

\section{RESULTS}

The age of the patients enrolled in this study ranged from 21-78 years: 21-70 years in TAPP group and 23-78 years in Lichtenstein's group. There were comparatively less patients in elderly group than in young and middle aged group with inguinal hernia. The mean age difference between the study groups is statistically insignificant (Table 1).

In both Lichtenstein's and TAPP group, the proportion of direct and indirect hernia are almost similar; around one-fifth of cases demonstrating direct hernia and around four-fifth exhibiting indirect (Figure 2).

In this study, over half of the patients had right sided hernia and slightly over a third have left sided hernia in both groups. Two percent of patients with bilateral hernia was treated in Lichtenstein's group and seven times more cases of bilateral hernia was operated in TAPP group (Figure 3).

Thus, figure 2 and figure 3 showed that indirect hernia and right sided hernia are common in both groups.

Table 2 compares the primary outcome of our study in both the groups and demonstrates that TAPP is superior to Lichtenstein's method in terms of post-operative pain score, hospital stay and quality of life. TAPP group had 
Transabdominal Pre-peritoneal Mesh Repair versus Lichtenstein's Hernioplasty

Table. 1 Distribution of patient according to age group $(n=102)$.

\begin{tabular}{|c|c|c|c|}
\hline \multirow{2}{*}{ Category of age group } & \multirow{2}{*}{ Age group (years) } & Lichtenstein's $(n=51)$ & TAPP $(n=51)$ \\
\hline & & No. of cases $(\%)$ & No. of cases (\%) \\
\hline \multirow{2}{*}{ Young age } & $\leq 30$ & $12(23.5)$ & $15(29.4)$ \\
\hline & $31-40$ & $8(15.7)$ & $4(7.8)$ \\
\hline \multirow{2}{*}{ Middle age } & $41-50$ & $5(9.8)$ & $15(29.4)$ \\
\hline & $51-60$ & $8(15.7)$ & $11(21.6)$ \\
\hline \multirow{3}{*}{ Elderly age } & $61-70$ & $12(23.5)$ & $5(9.8)$ \\
\hline & $71-80$ & $6(11.8)$ & $1(1.96)$ \\
\hline & Mean age & $49.20 \pm 18.18$ & $44.27 \pm 15.04$ \\
\hline$P$ value & 0.278 & of mean age) & \\
\hline
\end{tabular}

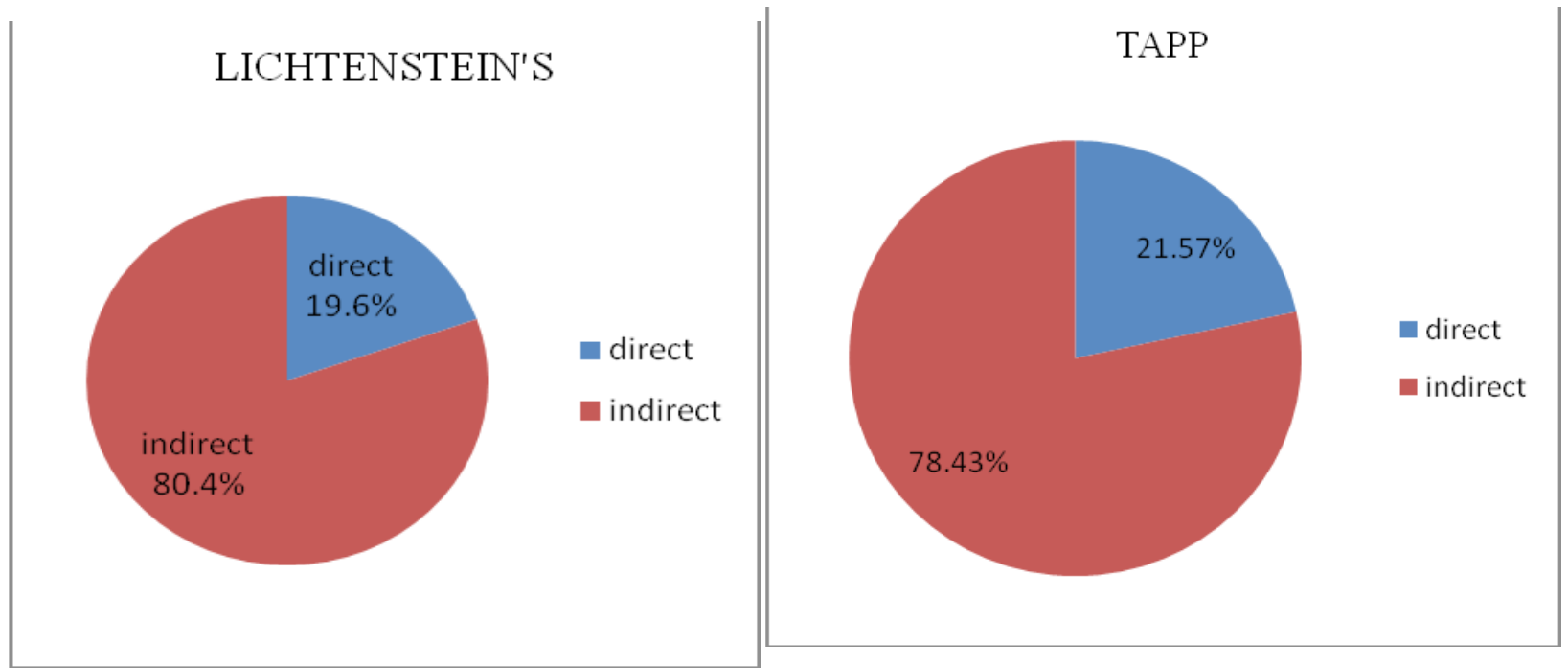

Figure 2. Differentiation of hernia according to type in both groups.
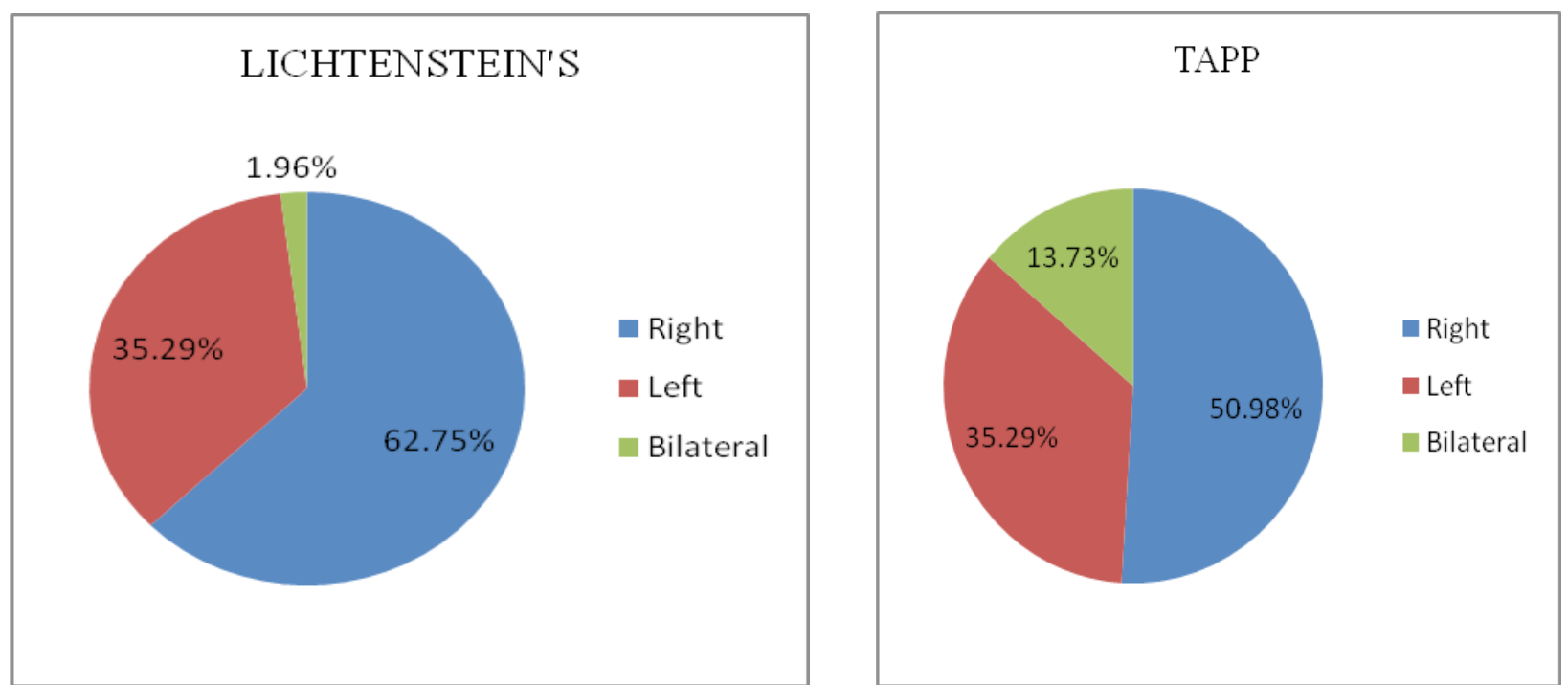

Figure 3. Differentiation of hernia according to side of hernia in both group. 
statistically significant low post-operative pain score, less hospital stay and early return to normal work. However, TAPP took significantly lengthier operative duration to repair hernia than Lichtenstein's group.

\begin{tabular}{|c|c|c|c|c|}
\hline \multicolumn{5}{|c|}{$\begin{array}{l}\text { Table 2. Comparison } \\
\text { Lichtenstein's and TAPP. }\end{array}$} \\
\hline $\begin{array}{ll}\text { Parameters } & \mathrm{Li} \\
\mathrm{he}\end{array}$ & $\begin{array}{l}\text { Lichtenstein's } \\
\text { hernioplasty }\end{array}$ & TAPP & & $P$ value \\
\hline $\begin{array}{l}\text { Mean } \\
\text { operative } \\
\text { duration } \\
\text { (minutes) }\end{array}$ & $42.55 \pm 5.95$ & 96.0 & .08 & $<0.001$ \\
\hline $\begin{array}{l}\text { Mean } \\
\text { hospital } \\
\text { stay (days) }\end{array}$ & $2.96 \pm 0.20$ & & .62 & $<0.001$ \\
\hline $\begin{array}{l}\text { Mean pain } \\
\text { score }\end{array}$ & $3.90 \pm 0.74$ & & .63 & $<0.001$ \\
\hline $\begin{array}{l}\text { Return to } \\
\text { normal } \\
\text { work (days) }\end{array}$ & $17.88 \pm 0.87$ & 13. & .60 & $<0.001$ \\
\hline \multicolumn{5}{|c|}{$\begin{array}{l}\text { Table 3. Comparison of complication between } \\
\text { Lichtenstein's and TAPP group. }\end{array}$} \\
\hline Complication & \multicolumn{2}{|c|}{$\begin{array}{l}\text { Lichtenstein's } \\
\text { (\%) }\end{array}$} & \multicolumn{2}{|c|}{ TAPP (\%) } \\
\hline Wound infection & \multicolumn{2}{|c|}{$2(3.92)$} & \multicolumn{2}{|c|}{ Nil } \\
\hline Seroma & \multicolumn{2}{|l|}{$1(1.96)$} & \multicolumn{2}{|c|}{ Nil } \\
\hline Conversion & \multicolumn{2}{|l|}{ Nil } & \multicolumn{2}{|c|}{1 (1.96) } \\
\hline Recurrence & \multicolumn{2}{|l|}{ Nil } & \multicolumn{2}{|c|}{$3(5.88)$} \\
\hline
\end{tabular}

There were two wound infections and one seroma formation in conventional group whereas in TAPP group there were three recurrence (one after 3 months, one after 2 weeks and one after one year of surgery) and one conversion due to adhesion (Table 3). Both infections were superficial surgical site infection (SSI) involving only skin and subcutaneous fascia. Both SSI were diagnosed on the third postoperative day during wound inspection; swab was taken and sent for culture but no growth was seen in both cases. No drain was kept after TAPP. Recurrence was confirmed both clinically and radiologically with ultrasound. Recurrent cases were managed with Lichtenstein's hernioplasty.

\section{DISCUSSION}

After the advent of minimally invasive surgery (MIS), open surgery has been gradually replaced by laparoscopic surgery. In our study there were 51 TAPP and 51 Lichtenstein's hernioplasty in study duration of 24 months.

The mean age in Lichtenstein's group was $49.20 \pm 18.19$ years, where as in TAPP it is $44.27 \pm 15.04$ years. This finding is consistent with a randomized multicenter trial (SCUR Hernia Repair Study) $)^{13}$ which also showed that most hernia occurred in patients above 45 years of age, and the mean age in Lichtenstein's group and TAPP group was $57.1 \pm 9.6$ and $55.9 \pm 9.7$, respectively.

Our study showed that indirect inguinal hernia and right sided hernia are the most common hernia in our patients. These findings are consistent with the various other studies from Nepal, Korea and India. ${ }^{14-16}$

Our study also significantly showed the operative duration for TAPP hernia repair was longer (almost twice) than that of conventional repair and the result was in accordance to various other studies. ${ }^{17-20}$ However, a Roman experience on open and TAPP repair ${ }^{21}$ showed no significant difference between the two methods.

Pain was analyzed by using Visual Analogue Score. In our study, cumulative score for 24 hours was analyzed. Significant difference in pain score with low pain score in TAPP group was seen in our study $(2.00 \pm 0.63$ vs $3.90 \pm 0.73$, $P$ value $<0.001$ ) which is consistent with an Egyptian study ${ }^{17}$ showing $20 \%$ vs $5 \%$ severe pain, with $P$ value 0.04 which is statistically significant. Another study done in the United States from 1991 - $1993^{22}$ also showed less post-operative pain in TAPP group with $\mathrm{P}$ value $<0.001$. A meta-analysis from 41 eligible controlled trials comprising of 7161 participants ${ }^{20}$ also showed less persisting pain ( $P$ value $<0.0001$ ), and less persisting numbness ( $P$ value $<0.0001$ ) in the laparoscopic groups.

In our study, patients were charged same amount for both Lichtenstein's and TAPP but if we take into consideration of the charge of materials used in TAPP (like preformed mesh, V Loc suture and tacker), it is around 6 times more expensive than Lichtenstein's repair. Most of the present studies have showed that TAPP is far costly than open method. A prospective, non-randomized trial conducted in Harvard Medical School in early $90 \mathrm{~s}^{23}$ also showed that laparoscopic hernia repair is far expensive $(\$ 4165+/$ $\$ 1154$ vs $\$ 2985+/-\$ 1682 ; \mathrm{P}$ value $<.05)$, and required more post-operative admissions (28\% vs $3.5 \%)$ causing more financial burden, which is supported by SCUR Hernia Repair Study (435.38 vs 52.13 USD) ${ }^{13}$ published on 1999. In our study, average hospital stay in TAPP and Lichtenstein's group was $2.33 \pm 0.62$ and $2.96 \pm 0.20$; $P$ value $<0.001$, respectively. This finding is consistent 
with finding of SCUR Hernia Repair Study ${ }^{13}$ showing 3.43 hours difference in time to discharge from hospital $(P$ value $=0.029)$. A meta-analysis ${ }^{20}$ showed the length of hospital stay did not differ between the groups (WMD -0.04 days; $P$ value $=0.05$, but return to usual activity was earlier for laparoscopic groups (HR 0.56; P value $<0.0001$ - equivalent to 7 days).

In our study, there was early return to normal work in TAPP group than in Lichtenstein's group $(13.39 \pm 0.60$ vs $17.88 \pm 0.87$ days, $P$ value $<0.001)$. This finding is consistent with the Italian study ${ }^{21}$ which showed early return to normal work in TAPP group ( 9.8 vs 13.4 days). A study from Harvard Medical School ${ }^{23}$ also showed earlier return to normal work in laparoscopic group than in conventional repair (5.6 vs 10.3 days, $\mathrm{P}$ value $<0.05$ ).

In our study, there were $3(5.88 \%)$ complications in Lichtenstein's group (wound infection and seroma) and there was one $(1.96 \%)$ conversion in TAPP group due to adhesion. This finding is consistent with a meta-analysis of 29 randomized clinical trials published on $2003^{17}$ which shows significant reduction of post-operative complications in laparoscopic group by $38 \%$ (95 per cent confidence interval $(\mathrm{Cl}): 0.46$ to 0.84 ; $\mathrm{P}$ value $=0.002$ ) Another study from Rome ${ }^{21}$ also showed that the postoperative complication rate was $4.5 \%$ in open group patients and 3\% in TAPP group. However, a study done in Egypt $^{17}$ showed $45 \%$ cases having seroma in TAPP group and $5 \%$ in conventional group which was contrary to our finding with $2 \%$ seroma in open group and no seroma formation in TAPP group.

In our study, we had $3(5.88 \%)$ recurrence in TAPP and no recurrence in Lichtenstein's group, i.e. more recurrence in TAPP group. This finding is consistent with the Harvard surgeon's experience ${ }^{23}$ showing $6.38 \%$ recurrence in laparoscopic group and no recurrence in Lichtenstein's group. However, an Italian surgeon ${ }^{21}$ experienced no significant difference in recurrence in group, $0.6 \%$ in open group and $0.4 \%$ in TAPP group. Contrary to both, SCUR Hernia Repair Study ${ }^{13}$ showed high recurrences in open group, most of them occurring during first 6 months (5.5\% vs $2 \%)$.

\section{CONCLUSIONS}

This study has shown that TAPP is more effective as it reduces hospital stay, early return to normal work, reduced complications like seroma and SSI in patients undergoing TAPP repair in short follow-up. However, operative duration is prolonged in TAPP group.

\section{REFERENCES}

1. Gadwal NV. A study on symptoms and etiological profile of ventral hernia cases. IntJ Curr Res Aca Rev. 2015;3:293-7.

2. Hee RV. History of inguinal hernia repair. Jurnalul de Chirurgie. 2011;7:301-19. [Link]

3. Malangoni MA, Rosen MJ. Hernias. In: Townsend CM, Beauchamp RD, Evers BM et al,. Sabiston Text Book of Surgery: The Biological Basis of Modern Surgical Practice. 19th ed. Philadelphia: Elsevier Saunders; 2012.

4. Lau WY, Leow CK, Li AK. History of endoscopic and laparoscopic surgery. World J Surg. 1997;21: 444-53. [Link]

5. Lau WY. History of treatment of groin hernia. World J Surg. 2002;26: 748-59.[Link]

6. Gray SH, Hawn MT, Itani KM. Surgical progress in inguinal and ventral incisional hernia repair. Surg Clin North Am. 2008;88: 17-26.[Link]

7. Haller JO, Kassner G, OstrowitzA, Kottmeler K, Perfschuk LP. Pilomatrixoma (calcifying epithelioma of Malherbe): radiographic features. Radiology. 1977;123:151-3.[Link]

8. Filipi CJ, Fitzgibbons RJ,Jr., Salerno GM, Hart RO. Laparoscopic herniorrhaphy. Surg Clin North Am. 1992;72:1109-24.[Link]

9. Felix EL, Michas C. Double-buttress laparoscopic herniorrhaphy. J Laparoendosc Surg. 1993;3:1-8.[Link]

10. Arregui ME, Navarrete J, Davis CJ, Castro D, Nagan RF. Laparoscopic inguinal herniorrhaphy. Techniques and controversies. Surg Clin North Am. 1993;73: 513-27. [Link]

11. Spaw AT, Ennis BW, Spaw LP. Laparoscopic hernia repair: the anatomic basis. J Laparoendosc Surg. 1991;1: 269-77. [Link]

12. Bittner R, Schmedt CG, Leibl BJ. Transabdominal preperitoneal approach. In: LeBlanc KA, editor. Laparoscopic hernia surgery. An operative guide. $1^{\text {st }}$ ed. Arnold Publication; 2003:p. 53-64.

13. Johansson B, Hallerback B, Glise H, Anesten B, Smedberg $\mathrm{S}$, Roman J. Laparoscopic mesh versus open preperitoneal mesh versus conventional technique for inguinal hernia repair:a randomized multicenter trial (SCUR Hernia Repair Study). Ann Surg. 1999;230: 225-31.[Link]

14. Shakya VC, Sood S, Bhattarai BK, Agarwal CS, Adhikary S. Laparoscopic inguinal hernia repair: a prospective evaluation at Eastern Nepal. Pan Med J. 2014;17: 241. [Link]

15. Choi YY, Han SW, Bae SH, Kim SY, Hur KY, Kang GH. Comparison of the outcomes between laparoscopic totally extraperitoneal repair and prolene hernia system for inguinal hernia; review of one surgeon's experience. 
Journal of the Korean Surgical Society. 2012 Jan 1;82(1):40-4. [Link]

16. Beeraka C, Surapaneni S, Raavi R. Repair of a primary inguinal hernia by using a polypropylene mesh: a tension free Lichtenstein repair in rural Andhra Pradesh. Clin Diagn Res. 2012;6: 261-3.

17. Elwan AM, Abomera MA, Abo Al Makarem MA, Mohammedain AH. Laparoscopic transabdominal preperitoneal repair versus open preperitoneal mesh repair for inguinal hernia. J Arab Soc Med Res. 2013;8: 38-42.[Link]

18. Memon MA, Cooper NJ, Memon B, Memon MI, Abrams KR. Meta-analysis of randomized clinical trials comparing open and laparoscopic inguinal hernia repair. Br J Surg. 2003;90: 1479-92.

19. Hamza Y, Gabr E, Hammadi H, Khalill R. Four-arm randomized trial comparing laparoscopic and open hernia repairs. Int J Surg. 2010; 8: 25-28.[Link]

20. McCormack K, Scott N, Go PM, Ross SJ, Grant A. Laparoscopic techniques versus open techniques for inguinal hernia repair. The Cochrane Library. 2003. [Link]
21. Pironi D, Palazzini G, Panarese A, La Gioia G, Vendettuoli $\mathrm{M}$, Romani AM et al. Open mesh technique versus laparoscopic transabdominal preperitoneal (TAPP) approach in inguinal hernia repair. Our experience. G Chir. 2008;29: 497-504.[Link]

22. Millikan KW, Kosik ML, Doolas A. A prospective comparison of transabdominal preperitoneal laparoscopic hernia repair versus traditional open hernia repair in a university setting. Surg Laparosc Endosc. 1994;4: 247-53. [Link]

23. Brooks DC. A prospective comparison of laparoscopic and tension-free open herniorrhaphy. Arch Surg. 1994;129:361-66.[Link] 